\title{
Inovação e identidade vitivinícola da Festa Nacional da Uva de Caxias do Sul (Rio Grande do Sul, Brasil): os cursos de degustação de vinhos como estratégias de Turismo de Experiência
}

\section{Innovation and identity of the National Grape Festival of Caxias do Sul (Rio Grande do Sul, Brazil): the wine tasting courses as strategies of Experience Tourism}

\author{
Edegar Luis Tomazzoni (TOMAZZONI, E. L.) ${ }^{*} \mathrm{e}$ \\ Silvia Helena Zanirato (ZANIRATO, S. H.) ${ }^{* *}$
}

\begin{abstract}
RESUMO - O objetivo deste artigo é analisar a eficácia dos cursos de degustação de vinhos no contexto de gestão e de inovação das atrações vitivinícolas da Festa Nacional da Uva, de Caxias do Sul (Rio Grande do Sul), Brasil. A Festa Nacional da Uva, de Caxias do Sul foi criada para melhorar a qualidade das uvas e dos vinhos brasileiros. De acordo com autores da história do evento, como Adami (1975) e Ribeiro (2002), a primeira edição realizou-se em 1931, e, conforme a Comissão Organizadora, responsável pela realização da Festa da Uva, em 2014, realizou-se a $30^{\text {a }}$ edição do evento, com 700 expositores e 650 mil visitantes. Em 2000, criaram-se os cursos de degustação de vinhos. Os métodos de pesquisa foram os de pesquisa ação, observação direta e análise de conteúdos das falas de organizadores e de gestores das vinícolas expositoras, bem como de matérias da imprensa. Verificou-se que, além de inovação incremental e estratégia de merchandising, os cursos agregam valor à programação do evento e à oferta do turismo de experiência vitivinícola regional.
\end{abstract}

Palavras-chave: Vinho; Inovação; Turismo de Experiência; Festa da Uva; Caxias do Sul (Brasil).

ABSTRACT - The aim of this paper is to analyze the effectiveness of the wine tasting courses in the context of management and innovation of wine attractions of National Grape Festival of Caxias do Sul (RS), Brazil. The National Grape Festival of Caxias do Sul was created to improve the quality of the grapes and Brazilian wines. According to

\footnotetext{
* Formação: Graduação em Engenharia Química pela Pontifícia Universidade Católica do Rio Grande do Sul (PUCRS), Especialização em Administração pela Universidade Federal do Rio Grande do Sul (UFRGS), Mestrado em Turismo pela Universidade de Caxias do Sul (UCS) e Doutorado em Ciências da Comunicação com Ênfase em Turismo pela Escola de Ciências e Comunicações (ECA) da Universidade de São Paulo (USP). Atividade profissional: Docente do Mestrado em Mudança Social e Participação Política; do Mestrado em Turismo e do Curso de Graduação em Lazer e Turismo, na Escola de Artes Ciências e Humanidades (EACH), da Universidade de São Paulo (USP). Endereço físico para correspondência: Rua Arlindo Bettio, 1000, sala T10 D, bloco A1. CEP: 03828-080 - São Paulo - SP (Brasil). Telefone para contato: 1111 3091-3195. E-mail: eltomazzoni@usp.br

** Formação: Graduação em História pela Universidade Estadual Paulista (UNESP), Especialização em Gestão do Patrimônio Cultural Integrado pela Universidade Federal de Pernambuco (UFPE) e Doutorado em História pela Universidade Estadual Paulista Júlio de Mesquita Filho e Pós-Doutorado em Geografia Política pela Universidade de São Paulo (USP) e em História pela Universidad de Sevilla (Espanha). Atividade profissional: Docente do Curso de Gestão Ambiental (EACH) e dos Programas de Pósgraduação em Ciência Ambiental e em Mudança Social e Participação Política, ambos da USP. Endereço físico para correspondência: Rua Arlindo Bettio, 1000, sala T04, bloco A1. CEP: 03828-080 - São Paulo - SP (Brasil). Telefone para contato: 1111 3091-3195. E-mail: shzanirato@usp.br
} 
the history of the event authors (Adami 1975; Ribeiro 2002), the first edition was held in 1931, and in 2014 was the 30th edition of the event, with 700 exhibitors and 650,000 visitors. In 2000, were created the wine tasting courses. The research methods were action research, direct observation and content analysis of interviews with organizers and managers of the exhibiting wineries and articles published by the press. In addition to incremental innovation and merchandising strategy, the courses attract tourists, adding value to the event programming and to the winery regional experience tourism.

Key words: Wine; Innovation; Experience Tourism; Grape Festival; Caxias do Sul (Brazil). 


\section{INTRODUÇÃO}

A tradição do vinho, como bebida presente desde as celebrações dos primórdios da história da humanidade e evocada também em passagens bíblicas (o primeiro milagre de Cristo foi transformar água em vinho), e seu reduzido consumo per capita no Brasil (dois litros por habitante por ano), comparativamente a outros países (na Argentina são 25 litros por habitante por ano), são, conforme a Comissão Organizadora da Festa da Uva (FESTA DA UVA, 2014; CAXIAS DO SUL, 2104), responsável pela realização do evento e o Instituto Brasileiro do Vinho (IBRAVIN, 2014), justificativas da realização dos cursos de degustação. O município, de 434 mil habitantes é pólo da Serra Gaúcha, segunda economia do Rio Grande do Sul, 34 ${ }^{\text {a }}$ economia do Brasil e quarto maior produtor de uvas e de vinhos do país (CIC, 2014; IBGE, 2014; FEE, 2014).

A Festa da Uva, criada em 1931, é pioneira, uma das maiores do gênero do Brasil e o principal evento do município (OCORRÊNCIAS, 1998; CENAS, 2000; ALVES e TONET, S/D; TOMAZZONI, 2003; ZOTTIS, 2009; SECRETARIA DE TURISMO, 2014; CAXIAS DO SUL, 2014; ATUASERRA, 2014; BRASIL, 2014). Das 800 atividades de sua programação, os cursos de degustação de vinhos, cuja finalidade didático-pedagógica, com base na estratégia de merchandising, é promover o consumo da bebida, é uma de suas atrações mais significativas (IBRAVIN, 2014; SHRBS, 2104; FESTA DA UVA, 2014).

Além de realizar-se no centro da principal região produtora de uvas e vinhos do Brasil (EMBRAPA e AGEITEC, 2014), a Festa da Uva de Caxias do Sul reúne públicos diversificados, cujos interesses, desejos e expectativas variam, desde o conhecimento de novas tecnologias de produção vitivinícola, até o desfrute do lazer, gastronômico, cultural e artístico (TOMAZZONI, 2003; CAXIAS DO SUL, 2014; SHRBS, 2014; FESTA DA UVA, 2014).

O objetivo deste artigo é analisar os cursos de degustação de vinhos, no contexto de inovação das atrações vitivinícolas da Festa Nacional da Uva, de Caxias do Sul (Rio Grande do Sul), Brasil. Com esse objetivo analisou-se a atividade gastronômica como estratégia do turismo de experiência, componente criativo e inovador da festividade. 
Para a elaboração do texto, além de revisão bibliográfica e documental, o método de pesquisa consistiu em: pesquisa ação, observação direta, análise de conteúdo de falas de organizadores da Festa e de gestores das vinícolas expositoras e de matérias veiculadas na imprensa.

A análise de conteúdo foi utilizada para descrever e interpretar textos, documentos e respostas. A análise de conteúdo orienta-se por critérios como: contexto, objeto ou corpus, sujeitos entrevistados, questões formuladas, objetivos da pesquisa, subjetividade e isenção científica do pesquisador (BARDIN, 1977; BARROS e LEHFELD, 1991; MORAES, 1994).

A análise de conteúdo e a análise do discurso são métodos qualitativos aplicados para interpretar o conteúdo dos textos e documentos. Essas análises orientam-se por critérios como: contexto, objeto ou corpus, sujeitos entrevistados, questões formuladas, objetivos da pesquisa, subjetividade e isenção científica do pesquisador (BARDIN, 1977; BARROS e LEHFELD, 1991; MORAES, 1994).

Para a interpretação e entendimento das informações de caráter conotativo e denotativo, é necessário que se tenha conhecimento do assunto, ou da realidade sobre a qual os conteúdos verbais e escritos tratam. É, portanto, função das análises de conteúdo e do discurso aplicar os conceitos teóricos à interpretação da realidade que se descreve (FAIRCLOUGH, 2001).

Os procedimentos da história oral priorizam, "através da construção de fontes e documentos, registrar as narrativas induzidas e estimuladas, testemunhos, versões e interpretações sobre a História em suas múltiplas dimensões: factuais, espaciais, conflituosas, consensuais" (DELGADO, 2006, p. 21). O trabalho com a história oral, para Alberti (2004), consiste no registro de depoimentos de caráter histórico e documental com atores ou testemunhas de acontecimentos, fatos, modos de vida da história contemporânea. A memória é a matéria-prima privilegiada.

Outro procedimento fundamental foi a pesquisa ação. Para Dencker (2007, p. 155) "pesquisa ação é pesquisa empírica com estreita vinculação a uma ação ou resolução de um problema coletivo. Os pesquisadores e participantes representativos da situação ou do problema estão envolvidos de modo cooperativo ou participativo".

O autor deste artigo participou das Comissões Organizadoras das edições de 1984, 1986, 1994 e 1996 e é o responsável pela realização dos Ciclos de Estudos 
Turísticos de Caxias do Sul e da Serra Gaúcha (1988 a 1990) e pelo projeto do Seminário Repensando a Festa da Uva (1990). Esse autor também coordenou as duas primeiras edições do Salão dos cursos de degustação de vinhos (2000 e 2002). Muitas das informações sobre essas atividades são inéditas, são publicadas exclusivamente neste artigo, com base em acervo próprio, uma vez que houve envolvimento direto e intenso do autor com o objeto de estudo, na condição de participante da organização de várias edições do evento. Diversas edições da Festa da Uva de Caxias do Sul foram analisadas pelo autor por meio do método de observação direta.

Para cumprir os objetivos, trata-se, primeiramente, dos sentidos dos eventos no campo da promoção turística, com destaque para o turismo de experiência. Na continuidade, apresenta-se histórico da festividade e sua consolidação. Na parte que segue, analisa-se a inserção dos cursos de degustação de vinhos como estratégia inovadora da programação da Festa da Uva. Nas considerações finais se aborda sobre a eficácia da atividade inovadora.

\section{INOVAÇÃO, EVENTOS E TURISMO DE EXPERIÊNCIA}

No campo do turismo, eventos são planejados e organizados para reunir pessoas com interesses comuns, visando a dinamizar a cadeia produtiva do setor. São estratégias de marketing turístico, que promovem produtos e serviços, projetam a imagem dos destinos, contribuem para o fortalecimento da identidade e o desenvolvimento socioeconômico local (OLIVEIRA, 2001; ANDRADE, 2002; BRITO e FONTES, 2002; HALL, JOHNSON e MITCHELL, 2004; BENI, 2007).

Nas diversas modalidades de eventos, a articulação entre os atores - poder público, iniciativa privada, comunidade local, turistas - é fundamental para a gestão organizacional, a inovação dos atrativos e o sucesso das festas turísticas. A gestão democrática e participativa constitui modelo de cooperação entre atores representativos na realização de festas temáticas (OLIVEIRA, 2001; ANDRADE, 2002; BRITO e FONTES, 2002; HALL, JOHNSON, MITCHELL, 2004; BENI, 2007). 
Esses aspectos podem ser percebidos em eventos como os cursos de degustação de vinhos, estratégia de gestão e de inovação das atrações vitivinícolas da Festa Nacional da Uva, de Caxias do Sul (RS), Brasil.

A Festa Nacional da Uva foi criada, em 1931, com o propósito de melhorar a qualidade das uvas e dos vinhos brasileiros (ADAMI, 1975; OCORRÊNCIAS, 1998; CENAS, 2000; ALVES e TONET, S/D; RIBEIRO, 2002; ZOTTIS, 2009). Em 1990, como proposta do Ciclo de Estudos Turísticos, realizou-se o seminário Repensado a Festa da Uva (TOMAZZONI, 2002; MARANGON, 2010). A expectativa foi ampliar e fortalecer a participação dos produtores vitivinícolas e inovar os atrativos culturais. Aos poucos, outros elementos foram acrescentados ao evento, como a feira agroindustrial, a programação artística, o desfile de carros alegóricos e os cursos de degustação de vinhos, apresentados como diferenciais de inovação (TOMAZZONI, 2002; TRIGUEIRO, 2010; SHRBS, 2014; FESTA DA UVA, 2014).

Na edição da Festa da Uva de 2000, realizou-se o primeiro salão de cursos de degustação de vinhos, sucedido por pesquisas de satisfação com os turistas, que confirmaram a eficácia da ação como uma forma de promover o consumo das marcas dos vinhos nacionais (TOMAZZONI, 2002).

A inovação é destacada como fator essencial para o desenvolvimento, especialmente, por meio dos campos das ciências exatas e da tecnologia industrial (SCHUMPETER, 1985). O desafio transcende a inovação incremental, que é formada por todas as mudanças e adaptações da tecnologia para melhoria progressiva de produtos e processos (VÁZQUEZ BARQUERO, 2001).

A inovação incremental é inerente ao aprendizado da empresa, e sua finalidade é atender às necessidades dos clientes. No campo industrial, sua definição fundamenta-se na capacidade competitiva, por meio de pequenas alterações nos processos de engenharia, no design de produtos e na utilização eficiente de matérias-primas (VÁZQUEZ BARQUERO, 2001).

Essa definição contribui para diferenciar esse conceito do sentido atribuído à inovação radical, que é a criação de produtos absolutamente novos, até então inexistentes no mercado (LEIFER; O’CONNOR; RICE, 2002). Nesse processo, de acordo com a idéia de destruição criadora de Schumpeter (1985), o antigo é radicalmente substituído pelo novo. A inovação radical é muito mais complexa e 
desafiadora para a competitividade empresarial e econômica do que a inovação incremental (LEIFER; O'CONNOR; RICE, 2002).

De acordo com Schumpeter (1985), são cinco as modalidades de inovação: 1) criação de novos produtos; 2) criação de novos métodos de produção; 3) descoberta de novas fontes de matéria-prima; 4) prospecção de novos mercados; e 5) novas formas de organização empresarial.

Uma das formas de inovação é a realização de eventos, que constitui um dos principais segmentos do mercado turístico, pois um evento turístico pode abranger públicos com interesses diversificados, e os atores responsáveis pela organização devem ter competências para administrar todos os aspectos, desde os de natureza temáticofestiva, até os de caráter técnico ou científico.

Para o planejamento de eventos temáticos, é fundamental a coesão entre o setor público, a iniciativa privada e o público alvo, determinando claramente as funções e as responsabilidades desses atores, considerando os retornos das iniciativas como premissas da cooperação. Um dos principais objetivos dos eventos é proporcionar difusão de informações, conhecimentos e aprendizado (TOMAZZONI, 2002; MAXIMIANO, 2004).

O turismo de eventos também é meio eficiente de promover a difusão de informações sobre determinada região ou localidade, abrir novas perspectivas sociais, desenvolver a criatividade, além de promover o sentimento de liberdade pelos novos contatos culturais (BENI, 2007).

Tal afirmativa é confirmada por Oliveira (2001 p. 75): “turismo de eventos é praticado por quem deseja participar de acontecimento promovido com o objetivo de discutir assuntos de interesses comuns (profissionais, culturais, desportivos), ou para expor e lançar novos produtos no mercado".

No mesmo sentido, Andrade (2002, p. 41) argumenta que "os eventos constituem parte significativa na composição do produto turístico, atendendo intrinsecamente às exigências de mercado em matéria de entretenimento, lazer, conhecimento, descanso".

Analogamente, para Brito e Fontes (2002, p. 14):

Muito mais que um acontecimento de sucesso, uma festa, uma linguagem de comunicação, uma atividade de relações públicas, ou mesmo uma estratégia 
de marketing, o evento é a soma de esforços e ações planejadas com o objetivo de alcançar resultados definidos junto ao seu público-alvo.

De acordo com Canton (2009, p. 211), os eventos apresentam-se como nichos para o mercado no campo do turismo:

\begin{abstract}
A realização de eventos culturais revela-se importante como nicho de mercado para diversos municípios, em se tratando do solo brasileiro, em que a miscigenação cultural se mostra diversificada. As localidades em que as comunidades sejam empreendedoras e inovadoras podem se beneficiar desses nichos, propondo a excelência no que se refere à hospitalidade e priorizando nova dinâmica social com reflexos econômicos e comerciais.
\end{abstract}

Desses conceitos, depreende-se que é para a sociedade que se integra cada vez mais pela rede mundial da informatização que se criam eventos, por meio de intercâmbios, parcerias e cooperação, visando a retornos abrangentes. Para a organização de eventos os gestores são desafiados a criar estratégias inovadoras, e o sucesso da proposta depende da inovação da programação de atrativos, em harmonia com sua essência ou identidade do espaço que os sediam e das pessoas que dele participam.

Os eventos são estratégias de marketing, pois aproximam fornecedores de produtos e serviços dos clientes, fortalecendo a fidelização de consumidores ou proporcionando a conquista de novos consumidores. Nesse contexto, o marketing constitui-se de diversas modalidades promocionais, ente as quais o merchandising, que é conjunto de técnicas para exposição destacada e agregação de valor a produtos (LOVELOCK; WRIGTH, 2001; KOTLER; KELLER, 2012). No caso de produtos gastronômicos, a demonstração e a degustação são técnicas eficazes. A ambientação de eventos turísticos, como as festas temáticas, potencializa a eficácia do merchandising de produtos gastronômicos (BLESSA, 2005; ZENONE; BUAIRIDE, 2005).

Nesse sentido, é importante contextualizar os eventos no turismo de experiência, cujo conceito surgiu do arcabouço da economia da experiência. Sua proposta é a participação ativa do consumidor, motivado pela oferta de produtos com nova formatação, visando a transcender o estímulo dos cinco sentidos e proporcionar envolvimento emocional (PANOSSO NETTO, 2010).

Para Goodney (2002, p. 50): 


\begin{abstract}
A maior fonte de diferenciação continua sendo a contribuição específica dos aspectos naturais, físicos e humanos de uma localidade. Algumas características centrais da comunidade local são exatamente o que o visitante quer ver, experimentar, compartilhar e talvez levar consigo. $\mathrm{O}$ visitante gosta de entrar em um mundo diferente do seu e de experimentar produtos desconhecidos.
\end{abstract}

Viver emoções e experimentar sensações inesquecíveis proporciona sentimentos especiais, quando em interação com a cultura do local onde a experiência acontece. Além da beleza dos cenários e dos conteúdos das informações turísticas, há a interação com aspectos da cultura local. Os eventos são estratégias inovadoras de turismo de experiência, porque os destinos turísticos não são constituídos somente por cenários naturais, mas por ambientes criados e, especialmente, de animação sensorial memorável.

As tipologias de eventos turísticos são tão diversas quanto os segmentos do setor, entre os quais, o enoturismo (HALL; JOHNSON; MITCHELL, 2004; LAVANDOSKI; TONINI; BARRETTO, 2012). No caso deste artigo, o evento tratado é de natureza temático-festiva, cuja fundamentação é artístico-cultural, com características promocionais de múltiplos produtos, especialmente as uvas, que são a razão da sua origem e realização. A exposição e a degustação de vinhos constituem a configuração enoturística do evento em estudo.

O enoturismo contextualiza-se no turismo gastronômico. A gastronomia é componente representativo da cultura da comunidade receptora dos turistas. Os alimentos locais têm implícita a possibilidade de "consumir simbolicamente" (SCHLÜTER, 2003). No caso da Festa da Uva, a uva e o vinho são os elementos da gastronomia mais representativos da cultura local. A degustação é uma forma de apreciar simbolicamente a cultura local, da região da Serra Gaúcha.

\title{
3 ASPECTOS HISTÓRICOS E ORGANIZACIONAIS DA FESTA DA UVA
}

Em Praga matou os primeiros parreirais, reportagem veiculada no Caderno Nordeste Gaúcho (JORNAL PIONEIRO, 1999, p. 6), registra-se que a primeira videira que os imigrantes italianos plantaram na região aqui analisada não deu frutos. As mudas, que eram de uma variedade européia, não resistiram às pragas e morreram. $\mathrm{O}$ 
hábito de beber vinho estava ameaçado, o que fez com que os moradores buscassem outras alternativas.

A solução foi encontrada pelo contato dos produtores com os colonos alemães do município vizinho de Feliz, que trouxeram à Serra Gaúcha a uva isabel, uma cultivar de uva tinta, conhecida por sua fácil adaptação ao clima e resistência às doenças. Em poucos anos, havia parreirais em vários lugares da região, garantindo, dessa forma, a manutenção do hábito herdado há séculos. Nascia, assim, a vitivinicultura na Serra Gaúcha (ADAMI, 1975; RIBEIRO, 2002; TOMAZZONI, 2002; VALDUGA, 2011).

Em Caxias do Sul, fundada por imigrantes italianos (que compreendia também Flores da Cunha e Farroupilha) a produção de uvas e de vinhos destacou-se como uma das principais atividades econômicas até a metade do século $\mathrm{XX}$, quando a indústria tornou-se o principal setor da economia do município (ADAMI, 1975; RIBEIRO, 2002; TOMAZZONI, 2002; VALDUGA, 2011).

Solução no início, a uva isabel transformou-se em problema. Como resistia às pragas, os vitivinicultores preferiam essa variedade, mas isso resultava em vinho de baixa qualidade (ADAMI, 1975; RIBEIRO, 2002; TOMAZZONI, 2003; VALDUGA, 2011).

Mesmo com a criação da estação experimental, que fornecia variedades viníferas, não foi fácil convencer os produtores e trocar a isabel. Esse foi um dos argumentos para a realização da Festa da Uva. Em março de 1931, o coletor estadual, Joaquim Pedro Lisboa, organizou a exposição no Recreio da Juventude, para divulgar outras uvas viníferas (ADAMI, 1975; OCORRÊNCIAS, 1998; JORNAL PIONEIRO, 1999; CENAS, 2000; RIBEIRO 2002; ZOTTIS, 2009).

A realização de eventos de natureza agroindustrial e comercial fazia parte das atividades comunitárias de Caxias do Sul, desde os primórdios da imigração italiana. Em 1881, havia se realizado a Primeira Exposição Caxiense (Primeira Exposição AgroIndustrial da Colônia Caxias) (ADAMI, 1975; OCORRÊNCIAS, 1998; CENAS, 2000). O evento aconteceu seis anos após a fundação do município, e ocupou duas salas de uma das casas da diretoria de terras e colonização, localizada na esquina da Avenida Júlio de Castilhos com a Rua Marechal Floriano, no centro da pequena cidade. O presidente da Província Sul Riograndense destinou uma verba de $\$ 86000$ réis de auxílio para a exposição, fato que foi considerado motivo de grande contentamento local. Além 
dos produtos da lavoura, foram expostos garrafas com graspa, com vinho tinto e branco, ferramentas agrárias, utensílios domésticos e industriais (ADAMI, 1975).

A segunda exposição aconteceu em 1886 e, periodicamente, a cada três ou quatro anos o evento foi reeditado, até novembro de 1925, quando se realizou sua décima edição (ADAMI, 1975; RIBEIRO, 2002). Em 7 de março de 1931, foi inaugurada a Décima Primeira Exposição Caxiense, na sede do Recreio da Juventude, denominada, desde então, Festa da Uva (ADAMI, 1975; OCORRÊNCIAS, 1998; CENAS, 2000, RIBEIRO, 2002). Iniciava-se, então, o evento de características pioneiras no contexto econômico e turístico do Brasil.

O estudo de Valduga (2011) destaca a Festa da Uva de Caxias do Sul, no contexto do desenvolvimento da cadeia produtiva vitivinícola e da economia da Serra Gaúcha. Para o autor:

\begin{abstract}
Esse primeiro evento teve um propósito pedagógico, no sentido de levar ao maior número de colonos os novos conhecimentos da área, além de tentar fazer com que eles abandonassem o cultivo da uva isabel. Somente assim seria possível competir com os vinhos importados. O intendente do município, Celeste Gobbato, no discurso de abertura do evento, evidenciou essa intencionalidade citando que a festa demonstrou sua utilidade para "estimular os viticultores a abandonar o fetichismo da isabel, limitando sua cultura à área considerável que ela já ocupa, para aproveitar outras videiras de qualidade superior". Gobbato enfatizou também os encantos da região com suas montanhas pitorescas tomadas por parreirais para os turistas. (VALDUGA, 2011, p. 124).
\end{abstract}

De 1931 até 1998 (com intervalo entre 1937 e 1950, em razão da 2a Guerra Mundial), a Feira Agro-Industrial, inserida na festa, mostrou, a cada três ou quatro anos, a diversidade da produção econômica caxiense (RIBEIRO, 2002). A indústria metalúrgica e automotiva (de implementos rodoviários, autopeças e veículos) teve participação mais expressiva desde a edição de 1950, como expressão da força econômica desse setor, que representa $70 \%$ do PIB do município (RIBEIRO, 2002; CIC, 2014).

A importância do evento pode ser aferida também pelo fato de que, em 1972, foi cenário da primeira transmissão em cores da televisão no Brasil, o que motivou, em 2012, a criação do tema "Uva, Cor, Ação" em comemoração aos 40 anos do acontecimento (FESTA DA UVA, 2014; CAXIAS DO SUL, 2014; SECRETARIA DE TURISMO, 2014). 
A participação das indústrias vinícolas havia sido destacada até a edição de 1986 (TOMAZZONI, 2002). Em grandes e sofisticados estandes, as empresas realizavam exposição e degustação de vinhos. Em 1989, a organização do evento foi questionada quanto à falta de destaque da exposição e ao acesso ao consumo de uva e vinhos (TOMAZZONI, 2002).

O espaço em que as críticas foram manifestadas foi o Ciclo de Estudos Turísticos de Caxias do Sul e da Serra Gaúcha, projeto originário dos Cursos de Formação de Guia de Turismo, realizado em Caxias do Sul e sediado na Câmara de Indústria, Comércio e Serviços (CIC), do município. O evento reuniu especialistas em turismo da região e do país que debateram os problemas e dificuldades do desenvolvimento do turismo municipal e regional (TOMAZZONI, 2002; MARANGON, 2010).

Um dos principais resultados desses debates se viu na terceira edição do Ciclo de Estudos Turísticos, em 1990, quando foi apresentada à direção da empresa Festa Nacional da Uva Turismo e Empreendimentos S. A, a proposta do seminário Repensando a Festa da Uva, em parceria com a Universidade de Caxias do Sul. O Seminário se voltou para aspectos sócio-culturais do maior evento turístico da região, e para a participação da comunidade. Foram discutidos a popularização do concurso da rainha, a criação do setor de degustação de uvas, a participação das comunidades do interior nos desfiles de carros alegóricos, a reformulação da feira agroindustrial, o enriquecimento da programação artística e o fortalecimento da participação das vinícolas como fatores fundamentais para o sucesso da Festa (TOMAZZONI, 2002; FESTA DA UVA, 2014).

A Festa continuou a realizar-se bienalmente. De 20 de fevereiro a 9 de março de 2014, com 300 expositores de uvas e 400 expositores de vários segmentos (entre os quais as vinícolas), realizou-se $30^{\text {a }}$ edição do evento, com público visitante estimado de 650 mil pessoas (FESTA DA UVA, 2014; CAXIAS DO SUL, 2014; SECRETARIA DE TURISMO, 2014).

Além da feira multisetorial, de produtos industriais e comerciais, as atrações do parque de exposições foram: exposição e venda de uvas, espaço para consumo gratuito de uvas (variedades isabel e niágara) e shows (apresentações artísticas) de grupos regionais e nacionais. Ao longo de quase 20 dias de evento foram mais de 800 
atividades artístico-culturais (FESTA DA UVA, 2014; CAXIAS DO SUL, 2014; SECRETARIA DE TURISMO, 2014; SHRBRS, 2014).

Entre as atividades diretamente ligadas à vitivinicultura, além dos cursos de degustação de vinhos no centro dos estandes das vinícolas expositoras, na Praça do Vinho, o projeto Sabor da Festa proporcionou aos visitantes por meio de explanações, vídeos, e degustação da fruta, conhecimentos das variedades de uvas cultivadas na região (FESTA DA UVA, 2014; CAXIAS DO SUL, 2014; SECRETARIA DE TURISMO, 2014; SHRBRS, 2014).

Os cursos, com duração de 30 minutos, realizaram-se de segunda a sexta-feira, às $15 \mathrm{~h} 30$ e aos sábados e domingos, às $15 \mathrm{~h} 30,17 \mathrm{~h}$ e $19 \mathrm{~h}$. Bordô, concord, niágara branca, niágara rosa, cabernet sauvignon, merlot, tannat, moscato branco, pinot noir, chardonnay, riesling itálico, itália, rubi, benitaka, ribol, isabel, lorena, moscato Embrapa e BRS violeta foram as variedades de uvas oferecidas. Essas mesmas variedades foram expostas em vitrines, em localização especial no pavilhão de exposições do evento. Os produtores das melhores variedades, como de costume em todas as edições, foram premiados. Os primeiros colocados, como forma de atualização e de qualificação, receberam, como prêmios, viagens a países em que a produção vitivinícola é tida como tecnologicamente avançada (FESTA DA UVA, 2014; CAXIAS DO SUL, 2014; SECRETARIA DE TURISMO, 2014; SHRBS, 2014).

\section{OS CURSOS DE DEGUSTAÇÃO DE VINHOS NA FESTA DA UVA E SUA DINÂMICA PEDAGÓGICA}

No Salão de Vinhos, nas duas primeiras edições dos cursos de degustação de 2000 e de 2002, as sessões (aulas) tinham duração de cerca de uma hora, com a participação de 60 a 100 pessoas. O espaço era equipado de acordo com as exigências de conforto, qualidade e hospitalidade. Inicialmente os participantes assistiam a um audiovisual sobre a história e a produção vitivinícola da Serra Gaúcha (TOMAZZONI, 2002).

Os vinhos degustados eram de vinícolas de Bento Gonçalves, Caxias do Sul, Garibaldi e Flores da Cunha, também expositoras da feira agroindustrial da Festa da 
Uva. Em seguida, o enólogo instrutor explicava o método didático e orientava a sequência de etapas para apreciação e conhecimentos de duas variedades de vinhos, um branco e um tinto. Por meio dos sentidos de visão, olfato e paladar, os participantes aprendiam a examinar a coloração, o aroma e o sabor dos vinhos. Além disso, eram informados sobre as uvas utilizadas para a produção, as formas de armazenamento, as temperaturas para adequada conservação dos vinhos e mitos e verdades sobre a harmonização de vinhos com alimentos (TOMAZZONI, 2002; FESTA DA UVA, 2014; SHRBS, 2014).

Ao final, os participantes preenchiam formulário de avaliação da aula, que abrangiam desde a estrutura do espaço e a competência do enólogo, a eficácia da explanação, o conteúdo do audiovisual, a qualidade e a contribuição da prática para o aprendizado sobre vinhos.

Ao longo de duas semanas de evento, mais de cinco mil pessoas - presentes em 120 sessões ou aulas (média de cinco a seis sessões por dia) - responderam um formulário contendo questões fechadas e algumas abertas, que permitiam expressar suas opiniões.

A satisfação foi unânime. Praticamente $100 \%$ dos participantes manifestaram agradecimentos e parabenizaram os organizadores pela iniciativa e pela oportunidade. Foram encontradas expressões como: "nunca imaginei que algum dia me tornaria consumidor de vinhos" e "de hoje em diante, não só vou beber vinhos, como vou recomendá-los aos amigos". Muitos turistas, por exemplo, do sudeste e do nordeste do Brasil, sugeriam que cursos semelhantes fossem realizados em seus estados e cidades.

Nas edições de 2004, 2006 e 2008, os cursos não foram oferecidos, e sua realização foi retomada nas edições de 2010, 2012 e 2014. De acordo com a direção do Sindicato de Hotéis, Restaurantes e Bares da Região Uva e Vinho (SHRBS, 2014), os espaços para as aulas passaram a ser mais compactos, com capacidade para 24 pessoas, em ambiente climatizado, com paredes em vidro, despertando a curiosidade dos visitantes que lotaram as salas (SHRBS, 2014; IBRAVIN, 2014). Nas edições de 2010 e 2012, havia formulário sucinto, que questionava o nível de satisfação dos participantes, cujas respostas foram somente bom e ótimo (SHRBS, 2014; IBRAVIN, 2014). Além disso, em todas as edições (desde a primeira, em 2000) a entrega de 
certificados proporcionou evidente contentamento e orgulho aos participantes (IBRAVIN, 2014).

Em 2014, esses cursos foram oferecidos em sala no centro de espaço, de 900 metros quadrados, denominado Praça de Vinhos. Coordenadas por sommelier, realizaram-se 35 aulas de uma hora, para turmas de 24 pessoas, às 16 horas e às 19 horas nos dias úteis e, aos sábados e domingos, também às 11 horas (SHRBS, 2014; IBRAVIN, 2014, CLICRBS, 2014). Os cursos foram gratuitos, e, além dos vinhos, os participantes degustaram espumantes e sucos.

Nos cursos da edição 2014, optou-se por valorizar e privilegiar as vinícolas expositoras da Praça de Vinhos: Nova Aliança, Forqueta, Lovatel, Caldaro, Tradição, Agroindústria Lucca, Vinícola Grutinha, Valle di Caldaro e Casagranda. As variedades oferecidas para degustação foram: cabernet sauvignon, merlot, tannat, chardonnay, sauvignon Blanc, moscato e lorena (FESTA DA UVA, 2014; IBRAVIN, 2014; SEAPA, 2014; SHRBS, 2014; UCS, 2014).

Para os expositores, conforme as entrevistas realizadas para a pesquisa deste artigo, da edição de 2014, os cursos são estratégias eficazes e produtivas de marketing, comprovadas pelo aumento da demanda e das vendas dos vinhos na própria exposição. Os maiores retornos foram considerados a divulgação, os contatos e as expectativas de aumento das vendas após a realização do evento, conforme as experiências das edições anteriores da Festa da Uva.

\section{ANÁLISE DA ESTRATÉGIA DE DEGUSTAÇÃO DE VINHOS NA FESTA DA UVA}

Esta análise é elaborada com base em: revisão bibliográfica e documental, métodos de pesquisa ação, observação direta, análise de conteúdo de falas (discursos) de organizadores da Festa da Uva, de gestores das vinícolas expositoras e de matérias veiculadas na imprensa.

Reitera-se que o autor deste artigo participou das Comissões Organizadoras das edições de 1984, 1986, 1994 e 1996 e é o responsável pela realização dos Ciclos de Estudos Turísticos de Caxias do Sul e da Serra Gaúcha (1988 a 1990) e pelo projeto do 
Seminário Repensando a Festa da Uva (1990). Este autor também coordenou as duas primeiras edições do Salão dos cursos de degustação de vinhos (2000 e 2002). Por meio do método de pesquisa ação e do método de observação direta, muitas das informações sobre essas atividades são inéditas. São publicadas exclusivamente neste artigo, com base em acervo próprio.

A Festa Nacional da Uva de Caxias do Sul pode ser considerada exemplo de inovação radical no Brasil, no campo de eventos temático-culturais e do turismo de experiência. Com base na fundamentação conceitual de eventos, a razão da criação da Festa da Uva foi a necessidade de novos conhecimentos pelos produtores de uvas do município e da região.

Seu objetivo teve sentido pedagógico e sua proposta estético-expositiva teve caráter didático. A exposição de variedades de uvas nobres visou a ensinar os produtores a melhorar a qualidade da matéria-prima dos vinhos nacionais, valorizando e incentivando esse segmento agroindustrial. Configurou-se, ainda na década de 1930, como o principal evento temático vitivinícola do Brasil e consolidou-se, em 1950, como um dos maiores eventos turísticos do país (ADAMI, 1975; RIBEIRO, 2002; TOMAZZONI, 2002; TRIGUEIRO, 2010; VALDUGA, 2011).

O êxito da iniciativa contribuiu para sua reedição e expansão de sua área e das atividades artístico-culturais que constituem sua programação. Em razão da conjugação de fatores diversos e da articulação de elementos estéticos, como o próprio cenário paisagístico e cultural da região, o evento transcendeu a atração do público local, além dos próprios produtores.

Os organizadores da Festa da Uva empenharam-se em preservar a identidade cultural da região, adaptando os modos de realização do evento às mudanças da sociedade industrial. As características de sua ambientação, representativa da identidade cultural da região de imigração italiana e da própria denominação que a diferencia no calendário turístico, favoreceram a criação, na edição de 2000, dos cursos de degustação de vinhos. A proposta dos cursos foi uma resposta à necessidade de inovação das atividades da programação do evento, que nem sempre tinham pleno sucesso, ou que, em algumas edições, era mais criticado pelos participantes do que em outras.

A adaptação às mudanças, em consonância com a manutenção dos componentes culturais, foi processo complexo, com momentos de crise, principalmente na edição de 
1989. Foi essa crise que motivou, em 1990, a discussão de seu futuro no Ciclo de Estudos Turísticos e ensejou a realização do Seminário Repensando a Festa da Uva, cuja conclusão foi a importância e a eficácia da gestão democrática e participativa do evento de caráter comunitário.

As diversas propostas do Seminário Repensando a Festa da Uva potencializaram as condições favoráveis para a criação dos cursos de degustação de vinhos, cuja primeira edição (denominada Salão do Vinho), tornou a edição de 2000 uma das mais marcantes da história do evento. Outras edições podem ser destacadas, como as de: 1931 (criação da festa); 1950 (consolidação pós-Segunda Guerra); 1972 (primeira transmissão da televisão a cores do Brasil), 1884 e 1986 (com expressiva participação das vinícolas da região); 1991 (revitalização após o seminário em que se repensou o evento); 2012 (40 anos da transmissão da festa pela televisão a cores). Todas as edições, porém, foram fundamentais para o sucesso e a consolidação do evento.

A edição de 2014 também foi especial, não somente porque os cursos de degustação de vinhos são objeto de estudo deste artigo, mas porque a repercussão do evento na mídia foi positiva. Os cursos de degustação foram destacados pela imprensa entre as motivações de visitação turísticas do evento.

Os cursos de degustação de vinhos da Festa da Uva, certamente, não são o único momento em que os interessados podem conhecer os produtos, ou analisar sua qualidade. As empresas vinícolas e as organizações do setor, como o Instituto Brasileiro do Vinho (IBRAVIN), realizam essa dinâmica pedagógica em eventos exclusivos, ou como parte da programação de outros eventos, como na Festa Nacional do Vinho (Fenavinho), de Bento Gonçalves; na Festa Nacional do Champanha (Fenachamp), de Garibaldi; e na Festa Nacional da Vindina (Fenavindima), de Flores da Cunha) (ATUASERRA, 2014).

Ainda que, entre os 650 mil visitantes da $30^{\text {a }}$ edição de 2014, os interesses, desejos e expectativas fossem diversos e até mesmo conflitantes, o público atraído pelos shows de artistas nacionais de estilos MPB, sertanejo, rock and roll e tradicionalista gaúcha, foi o mesmo que teve oportunidade de conhecer os produtos vinícolas e de participar dos cursos de degustação de vinhos (FESTA DA UVA, 2014; CLICRBS, 2014). 
Apesar de a capacidade ser de apenas 24 pessoas por aula, em duas três sessões por dia, os participantes foram constituídos de pessoas que valorizam o vinho e que têm influência em seu círculo de relacionamentos, ou que caracterizam como formadores de opinião, conforme demonstraram as pesquisas de satisfação das duas primeiras edições, em 2000 e em 2002. Um dado importante foi a representatividade dos efetivos e potenciais consumidores, cuja formação educacional média é de nível superior (SHRBS, 2014; IBRAVIN, 2014; FESTA DA UVA, 2014).

As opiniões dos turistas indicaram que os cursos são vivências memoráveis na composição dos atrativos de turismo de experiência (SHRBS, 2014; IBRAVIN, 2014; FESTA DA UVA, 2014). São propostas diferenciais de envolvimento direto do turista na dinâmica sensorial. Para o conhecimento dos vinhos, o ambiente da Festa da Uva e o cenário paisagístico e cultural da região estimulam a visão, o olfato e o paladar, por meio da degustação, como prática pedagógica sucinta e objetiva, com recursos didáticos de qualidade. Simbolicamente os participantes dos cursos degustam a cultura regional.

As atuações das organizações de ensino e pesquisa, como a universidade e os institutos especializados, são fundamentais para criação, planejamento, organização e gestão de estratégias inovadoras, como os cursos de degustação de vinhos, conforme se verifica nas edições de maior sucesso da Festa Nacional da Uva de Caxias do Sul.

\section{CONSIDERAÇÕES FINAIS}

O modelo de planejamento, de organização e de gestão da Festa Nacional da Uva de Caxias do Sul, pioneiro do gênero no Brasil, inspirou a realização de vários eventos no país. O envolvimento da comunidade, a inovação de seus atrativos, cujo diferencial é o próprio motivo de sua criação, são fundamentais para o êxito do evento. Nesse sentido, enfatizam-se os cursos de degustação de vinhos e os espaços de exposições de produtos vitivinícolas regionais.

A Festa da Uva de Caxias do Sul é considerada exemplo de inovação radical, no campo dos eventos temáticos e turísticos. Em trinta edições, ao longo de quase 85 anos, o evento superou crises de gestão e de preservação de identidade, em razão da articulação simétrica de poderes entre as organizações públicas e privadas, coordenadas 
pela Prefeitura Municipal, que detém o controle acionário da empresa Festa Nacional da Uva Turismo e Empreendimentos S. A. (CAXIAS DO SUL, 2014; FESTA DA UVA, 2104).

Foi no contexto inovador radical do sistema de atividades do evento, não somente na época em que foi criado, no início da década de 1930, mas nas décadas seguintes, que, entre as modalidades de inovação incremental, criaram-se os cursos de degustação de vinhos. Além de proporcionar mais satisfação ao público participante, desde a edição de 2000, os cursos são estratégias de merchandising das indústrias vinícolas. Nesse sentido, as seis empresas que, na edição trigésima edição, em 2014, realizaram os cursos de degustação, representaram todo o setor produtivo de vinhos nacionais.

Tanto a Festa da Uva quanto os cursos de degustação têm-se viabilizado pela cooperação entre o poder público e as organizações privadas do setor, representadas especialmente pelo Instituto Brasileiro do Vinho (IBRAVIN).

Desde a primeira edição dos cursos, em 2000, quando compuseram o Salão do Vinho, realizaram-se oito edições da atividade. A estrutura, o número de vinícolas participantes e a frequência das aulas reduziram-se, ao longo de 14 anos, mas a representatividade cultural e econômica da iniciativa consolidou-se. É importante, porém, que se amplie a participação das indústrias vinícolas da Serra Gaúcha, por meio de maior apoio das entidades setoriais, além do IBRAVIN, que faz parte da organização e que tem dezenas de empresas associadas (IBRAVIN, 2014).

As mais de 800 atrações artístico-culturais e os mais de trinta motivos especiais da Festa da Uva de Caxias do Sul constituem ambiente favorável para preservar e fortalecer a proposta pedagógica e mercadológica dos cursos de degustação de vinhos. A exposição das variedades de uvas, cujas vitrines compõem o cenário do evento, potencializa a eficácia da proposta didática e proporciona vivência especial ao público visitante e turista, configurando-se em oportunidade de turismo de experiência.

Ainda que a capacidade fosse de 24 pessoas por aula, os 40 a 60 participantes por dia de evento são difusores das variedades de vinhos saboreados. Mais de $70 \%$ dos 650 mil visitantes da Festa da Uva são da própria região da Serra Gaúcha e do estado do Rio Grande do Sul, e 30\% são de outros estados (FESTA DA UVA, 2014). Os cursos de degustação de vinhos atraíram mais os turistas de outros estados, agregando valor à 
programação do evento e à oferta enoturística regional. A proposta lúdica da Festa da Uva torna o método ainda mais produtivo, pois os cursos de degustação constituem oportunidade de turismo de experiência, em que o participante saboreia o vinho, que simboliza a identidade cultural, a autenticidade gastronômica e a alma turística regional da Serra Gaúcha.

\section{REFERÊNCIAS}

ADAMI, J. S. Festas da Uva, 1881 a 1965. Caxias do Sul (RS): Editora São Miguel, 1975.

ALBERTI, V. Ouvir, contar: textos em história oral. Rio de Janeiro: FGV, 2004.

ALVES, E. R.; TONET, T. Z. Memorial Festa da Uva: sua memória, nossa história. Caxias do Sul: Editora São Miguel, s./d.

ANDRADE, R. B. Manual de eventos. Caxias do Sul (RS): EDUCS, 2002.

ATUASERRA - Associação de Turismo da Serra Nordeste do Rio Grande do Sul. Disponível em: <http://www.serragaucha.com/pt/paginas/caxias-do-sul/>. Acesso em: $16 / 08 / 2014$.

BARDIN, L. Análise de conteúdo. Lisboa: Edições 70, 1997.

BARROS, A. \& LEHFELD, N. Projeto de pesquisa: propostas metodológicas. Petrópolis: Vozes, 1991.

BLESSA, R. Merchandising no ponto de venda. São Paulo: Atlas, 2005.

BENI, M. C. Análise estrutural do turismo. São Paulo: SENAC, 2007.

BRASIL, Ministério do Turismo. Disponível em:

<http://turismo.gov.br/turismo/noticias/todas_noticias/20120217-2.html>. Acesso em: 26/08/2014.

BRITO, J.; FONTES, N. Estratégias para eventos: uma ótica do marketing e do turismo. São Paulo: Aleph, 2002.

CANTON, A. M. Eventos: ferramenta de sustentação para as organizações do terceiro setor. São Paulo: Roca, 2002.

CAXIAS DO SUL, Prefeitura Municipal. Disponível em: <http://www.caxias.rs.gov.br/>. Acesso em: 16/08/2014. 
Disponível em:

$<$ http://caxias.rs.gov.br/comunicacao/noticias_ler.php?codigo=22500>. Acesso em: 20/082014.

30 motivos para visitar a $3^{\mathbf{a}}$ Festa da Uva. Disponível em: $<$ http://www.caxias.rs.gov.br/comunicacao/noticias_ler.php?codigo=27408>. Acesso em: $26 / 08 / 2014$.

CENAS - Publicação do Arquivo Histórico Municipal João Spadari Adami, n. 5, jan. 2000.

CIC - Câmara de Indústria, Comércio e Serviços de Caxias do Sul. Perfil socioeconômico de Caxias do Sul. Disponível em: <http://www.ciccaxias.com.br/perfil/>. Acesso em: 27/08/2014.

CLICRBS. Dicas da Festa: degustação de vinho. Disponível em: $<$ http://wp.clicrbs.com.br/festanacionaldauva/2014/02/25/dica-da-festa-degustacao-devinho/?topo=51,1,1,171,17>. Acesso em: 25/08/2014.

CLICRBS. Pioneiro. Mais de 600 mil pessoas visitam a Festa da Uva, em Caxias do Sul. Disponível em: <http://pioneiro.clicrbs.com.br/rs/noticia/2014/03/mais-de-600-milpessoas-visitam-a-festa-da-uva-em-caxias-do-sul-4440789.html>. Acesso em: 26/08/2014.

DELGADO, L. A. N. História oral: memória, tempo, identidades. Belo Horizonte: Autêntica, 2006.

DENCKER, A. M. Pesquisa em turismo: planejamento, métodos e técnicas. São Paulo: Futura, 2007.

EMBRAPA - Empresa Brasileira de Agropecuária e AGEITEC - Agência Embrapa de Informação Tecnológica. Disponível em:

<http://www.agencia.cnptia.embrapa.br/gestor/uva_para_processamento/arvore/CONT0 00g56mkakt02wx5ok0dkla0saajvx4x.html>. Acesso em: 20/08/2014.

FAIRCLOUGH, N. Teoria social do discurso. In: FAIRCLOUGH, N. Discurso e mudança social. Brasília: Editora da UnB, 2001.

FEE - Fundação de Economia e Estatística Siegfried Emanuel Heuser. Disponível em: <http://dados.fee.tche.br/>. Acesso em: 26/08/2014.

FESTA NACIONAL DA UVA. História da Festa da Uva. Disponível em: $<$ http://www.festanacionaldauva.com.br/2014/sobre-a-festa/historia-da-festa $>$ Acesso em: $27 / 08 / 2014$.

GOODEY, B. Interpretação e comunidade local. In: MURTA, S. M.; ALBANO, C. (Orgs.). Interpretar o patrimônio: um exercício do olhar. Belo Horizonte: Ed. UFMG; Território Brasilis, 2002. 
HALL, M.; JOHNSON, G.; MITCHELL, R. Wine tourism and regional development. United Kingdom: Butterworth-Heinemann, 2000.

IBGE - Instituto Brasileiro de Geografia e Estatística. Cidades. Disponível em <http://www.cidades.ibge.gov.br/xtras/home.php>. Acesso em: 26/08/2014.

IBRAVIN - Instituto Brasileiro do Vinho. Disponível em: <http://www.ibravin.org.br/pt>. Acesso em: 16/08/2014.

LAVANDOSKI, J.; TONINI, H.; BARRETTO, M. Uva, vinho e identidade cultural na Serra Gaúcha (RS, Brasil). Revista Brasileira de Pesquisa em Turismo, v. 6, n. 2, 2012.

LEIFER, R.; O'CONNOR, G. C.; RICE, M. A implementação de inovação radical em empresas maduras. RAE - Revista de Administração de Empresas, v. 42, n. 2, 2002, p. $17-30$.

LOVELOCK, C. WRIGHT, L. Serviços: marketing e gestão. São Paulo: Saraiva, 2001.

MAXIMIANO, A. C. A. Teoria geral da administração. São Paulo: Atlas, 2004.

MARANGON, C. Repensando a Festa da Uva. Trabalho de Conclusão de Curso de Bacharelado em Turismo. Universidade de Caxias do Sul (UCS), 2010.

MORAES, R. Análise de conteúdo: limites e possibilidades. In: ENGERS, M. E. A. (Org). Paradigmas e metodologias de pesquisa em educação. Porto Alegre: EDIPUCRS, 1994.

OCORRÊNCIAS - Registros do Museu e Arquivo Histórico Municipal de Caxias do Sul, n. 15, jan 1998.

OLIVEIRA, A. Turismo e desenvolvimento: planejamento e organização. São Paulo: Atlas, 2001.

JORNAL PIONEIRO. Caderno Nordeste Gaúcho. 125 anos da Imigração Italiana. Praga matou os primeiros parreirais. Caxias do Sul, 17 de setembro de 1999.

PANOSSO NETTO, A. Experiência e turismo: uma união possível. In: PANOSSO NETTO, A.; GAETA, C. (Org.). Turismo de experiência. São Paulo: SENAC, 2010, p. $43-55$.

RIBEIRO, C. P. Festa e identidade: como se faz a Festa da Uva. Caxias do Sul: EDUCS, 2002.

SECRETARIA DE TURISMO de Caxias do Sul. Portal do Turista. Disponível em: <http://www.caxias.tur.br/\#>. Acesso em: 17/08/2014.

SCHLÜTER, R. Gastronomia e turismo. São Paulo: Aleph, 2003. 
SCHUMPETER J. A teoria do desenvolvimento econômico. São Paulo: Nova Cultural, 1985.

SEAPA - Secretaria de Agricultura, Pecuária e Agronegócio. Disponível em: <http://www.agricultura.rs.gov.br/>. Acesso em: 20/08/2014.

SHRBS - Sindicato de Hotéis, Restaurantes, Bares e Similares da Região Uva e Vinho. Disponível em: <http://sindiregiao.com.br/>. Acesso em: 20/08/2014.

TOMAZZONI, E. L. Organização de feiras de negócios: um modelo de gestão das feiras de negócios de Caxias do Sul. Dissertação de Mestrado. Programa de PósGraduação em Turismo da Universidade de Caxias do Sul (UCS), 2002.

- La Festa da La Uva en Caxias do Sul: tradición vitivinícola y turismo en Brasil. In: LACANAU, G. C; NORRILD, J. A. (Orgs.). Gastronomía y Turismo. Buenos Aires: CIET - Centro de Investigaciones y Estudios Turísticos, v. 1, 2003, p. $175-183$

TRIGUEIRO, O. M. Festa da Uva 2010. Nos trilhos da história, estação da colheita: os diferentes espaços folkcomunicacionais. Revista Eletrônica Temática. Ano VI, n. 11, 2010, p. 1 a 14.

UCS - Universidade de Caxias do Sul. Escola de Gastronomia. Disponível em: <http://www.ucs.br/site/ucs/extensao/escola_de_gastronomia/noticias/destaques >

Acesso em: 25/08/2014.

VALDUGA, V. Raízes do turismo no território do vinho: Bento Gonçalves e Garibaldi - 1870 a 1960 (RS/Brasil). Tese de Doutorado. UFRGS-PPGEO, 2011.

VÁZQUEZ BARQUERO, A. Desenvolvimento endógeno em tempos de globalização. Porto Alegre: UFRGS, 2002.

ZENONE, L. C.; BUAIRIDE, A. M. R. Marketing da promoção e merchandising. São Paulo: Thompson, 2005.

ZOTTIS, A. Festa da Uva de Caxias do Sul (RS): a memória de uma festa através de seus cartazes. Rosa dos Ventos, v. 1, n. 1, 2009, p. 1-34.

Recebido em: 15-05-2014.

Aprovado em: 13-06-2014. 